\title{
A comprehensive study on the oncogenic mutation and molecular pathology in Chinese lung adenocarcinoma patients
}

\author{
Xilin Zhang ${ }^{1+}$, Yan Jiang ${ }^{1 \dagger}$, Huanming $\mathrm{Yu}^{2}$, Hui Xia ${ }^{3}$ and Xiang Wang ${ }^{1 *}$ (D)
}

\begin{abstract}
Background: Several genetic driver alterations have been identified in micropapillary lung adenocarcinoma (MPA). However, the frequency of co-alteration of ROS1, EGFR, and EML4-ALK is yet unclear. Herein, we investigated the relationship between clinicopathologic characteristics and well-identified driver mutations of MPA compared with non-micropapillary lung adenocarcinoma (LA).

Methods: Formalin-fixed paraffin-embedded (FFPE) sections derived from lung adenocarcinoma patients who never received adjuvant chemotherapy or radiation therapy prior to surgical resection were collected from October 2016 to June 2019. EGFR mutations, ROS1 rearrangements, and EML4-ALK fusion were identified in a set of 131 MPA and LA cases by using the amplification refractory mutation system (ARMS). The response rate and duration of response were assessed using Response Evaluation Criteria in Solid Tumors version 1.1 (RECIST 1.1).

Results: EGFR mutations had occurred in 42 (76.4\%) MPA patients and 42 (55.3\%) LA patients. Interestingly, ROS1 rearrangements were highly enriched only in the MPA cases $(6 / 55,10.9 \%)$ but rarely in the LA cases $(1 / 76,1.3 \%)$. Furthermore, $7.3 \%$ (4/55) MPA samples had double gene mutations, while only 1.3\% (1/76) LA cases had double gene alterations. Of 5 patients with harboring two driver oncogene mutations, four patients (80\%) obtained partial response, and one patient (20\%) suffered recurrence.

Conclusions: A higher prevalence of ROS1 rearrangement or combined mutations of ROS1, EGFR, and EML4-ALK may play a critical role in the tumorigenesis of MPA. These findings provide a novel therapeutic strategy for patients with malignant MPA through combining TKls than one TKI.
\end{abstract}

Keywords: Lung adenocarcinoma, Micropapillary pattern, EGFR, ROS1, EML4-ALK

\section{Introduction}

Lung cancer remains to be the leading cause of cancerrelated death worldwide, and the most frequent histological subtype is lung adenocarcinoma [1]. Lung adenocarcinoma usually includes various histological subtypes, including solid, lepidic, acinar, papillary, and micropapillary patterns [2]

\footnotetext{
* Correspondence: xiangwhz@126.com

${ }^{+}$Xilin Zhang and Yan Jiang contributed equally to this work.

${ }^{1}$ Central Laboratory, The First People's Hospital of Huzhou, No. 158

Guangchang Back Road, Huzhou, 313000 Zhejiang, People's Republic of China

Full list of author information is available at the end of the article
}

according to the International Association for the Study of Lung Cancer (IASLC)/American Thoracic Society (ATS)/ European Respiratory Society (ERS) [3, 4]. Numerous studies have reported that lung adenocarcinoma with a micropapillary pattern (MPA) shows more aggressive behaviors and worse survival than other histological subtypes of lung adenocarcinoma (LA) [5-7].

Several oncogenic drivers have been identified in lung adenocarcinoma, including mutations in the epidermal growth factor receptor (EGFR) [8], fusions of anaplastic lymphoma kinase (ALK) [9], and rearrangements of ROS

(c) The Author(s). 2020 Open Access This article is licensed under a Creative Commons Attribution 4.0 International License, which permits use, sharing, adaptation, distribution and reproduction in any medium or format, as long as you give appropriate credit to the original author(s) and the source, provide a link to the Creative Commons licence, and indicate if changes were made. The images or other third party material in this article are included in the article's Creative Commons licence, unless indicated otherwise in a credit line to the material. If material is not included in the article's Creative Commons licence and your intended use is not permitted by statutory regulation or exceeds the permitted use, you will need to obtain permission directly from the copyright holder. To view a copy of this licence, visit http://creativecommons.org/licenses/by/4.0/ The Creative Commons Public Domain Dedication waiver (http://creativecommons.org/publicdomain/zero/1.0/) applies to the data made available in this article, unless otherwise stated in a credit line to the data. 
proto-oncogene 1 receptor tyrosine kinase (ROS1) [10]. Accumulating evidence demonstrated that mutations of EGFR were identified in 15-30\% of lung adenocarcinomas in Caucasians [11] and $40-60 \%$ in East Asians [12-14], indicating that the frequency of activated mutations of EGFR depends on ethnicity. Besides, ALK fusions were firstly identified in 2007 and occurred in approximately $3-7 \%$ of all lung adenocarcinoma patients, and the most common form was echinoderm microtubule-associated protein-like 4/anaplastic lymphoma kinase $(E M L 4-A L K)$ [15]. In the same year, an additional novel oncogenic fusion gene, ROS1, was identified, which accounted for $1-2 \%$ of all lung adenocarcinoma patients. Of special interest, this ratio increased to $5-7 \%$ for lung adenocarcinoma patients without EGFR/KRAS/BRAF/ALK mutations [16]. With the development of tyrosine kinase inhibitors (TKIs), TKIs served as the first-line option for patients harboring EGFR-sensitive mutations, $A L K$ fusions, or ROS1 rearrangements. Therefore, the discovery of TKIs against EGFR gene activation mutations (for example, gefitinib and erlotinib) [17] and $A L K$ or ROS1 gene rearrangements (for example, crizotinib) $[18,19]$ has significantly improved the outcomes of patients. For detection of ROS1 and EML4-ALK fusions, immunohistochemistry (IHC), next-generation sequencing (NGS), ARMSpolymerase chain reaction (ARMS-PCR), and fluorescence in situ hybridization (FISH) have been widely used [20]. Although FISH is the gold standard test, it is expensive and time-consuming. By contrast, ARMS-PCR is a more sensitive and feasible approach compared to FISH and IHC [21].

There is growing evidence that EGFR gene mutations are more common in MPA than in LA, while ROS1 gene rearrangement has not been clearly demonstrated in MPA patients [22-24]. Moreover, the co-existence of EGFR gene mutations, $A L K$ gene fusions, and ROS1 gene rearrangements has been reported in a few lung adenocarcinoma cases [25-27], but the co-alteration of ROS1, $E G F R$, and EML4-ALK in MPA remains unclear.

The molecular features of MPA may differ from other histopathological subtypes of lung adenocarcinoma [28]; however, the determinate information is not available. In the present study, we investigated the relationship between the most common driver mutations and the pathology features in Chinese lung adenocarcinoma patients.

\section{Materials and methods Patient selection}

A total of 131 lung adenocarcinoma patients were enrolled in the First People' Hospital of Huzhou from January 2016 to June 2019. Of them, 55 cases harbored at least 5\% micropapillary component [22], who were represented as MPA, and the remaining cases (43 solid,
20 acinar, and 13 lepidic) were defined as LA. All of them were initially diagnosed with lung adenocarcinoma and had not received neoadjuvant or adjuvant chemotherapy or radiation therapy prior to surgical resection. The pathological diagnosis was confirmed and classified using hematoxylin and eosin staining by two certified pathologists (Qilin Shi and Xiaolan Zhang from the First People's Hospital of Huzhou) based on the IASLC/ATS/ ERS multidisciplinary classification system [3]. All specimens contained $60 \%$ of tumor cells and sufficient tissues for further mutational analysis. Clinical information collected includes age, gender, tumor differentiation, tumor size, smoking history, lymphatic invasion, pleural invasion, tumor node metastasis (TNM) stage, micropapillary pattern, and prognostic data. This study was undertaken with the agreement of our hospital ethics committee, and the informed consent signature was provided by all patients.

\section{Evaluations of treatment}

After surgical resection, 5 patients were treated with 3 months chemotherapy following with targeted therapy (TKIs). Tumors were evaluated during the treatment with chemotherapy, EGFR-TKIs or ROS1/EML4-ALK inhibitors every 6 weeks. Efficacy was obtained using CT scan according to the Response Evaluation Criteria in Solid Tumors version 1.1(RECIST 1.1) [29]. Objective response rate (ORR) included complete response (CR), partial response (PR), stable disease (SD), and progressive disease (PD).

\section{Mutational analysis}

For EGFR mutation analysis, DNA from FFPE tissue sections was extracted by using a QIAamp DNA FFPE tissue kit (cat. No. 56404, Qiagen, Germany) according to the manufacturer's instructions. EGFR mutations within exons 18-21 were identified with commercial kits (Human EGFR mutation Detection Kit, cat. No. YZYMT-002-A, YZY Medical Co., Ltd., Wuhan, China) using ARMS. It was capable of detecting the following mutations: three in exon 18 (G719S, G719C, and G719A), one deletion in exon 19, two mutations in exon 20 (T790M and S768I), three insertions in exon 20, and two mutations in exon 21 (L858R and L861Q). Briefly, ARMS-PCR amplification (37 ${ }^{\circ} \mathrm{C}$ for $10 \mathrm{~min} ; 95^{\circ} \mathrm{C}$ for $5 \mathrm{~min} ; 40$ cycles of $95^{\circ} \mathrm{C}$ for $15 \mathrm{~s}$, and $60{ }^{\circ} \mathrm{C}$ for $60 \mathrm{~s}$ ) was performed using the 7500 system (Applied Biosystems; Thermo Fisher Scientific, Inc.). For EML4-ALK and ROS1 fusion analysis, RNA was isolated from FFPE sections by applying a RNeasy FFPE tissue kit (cat. No. 73504, Qiagen, Germany) according to the standard procedure. Complementary DNA was reversetranscribed using the PrimeScript RT reagent kit (Takara Biotechnology Co., Ltd.), according to the manufacturer's protocol. RNA (500 ng), $2 \mu \mathrm{l}$ PrimeScript ${ }^{\mathrm{TM}}$ RT Master 
Mix (Perfect Real Time) (Takara Biotechnology Co., Ltd.), and RNase free water (up to $10 \mu \mathrm{l}$ ) were mixed together and incubated at $37^{\circ} \mathrm{C}$ for $15 \mathrm{~min}$ and $85^{\circ} \mathrm{C}$ for $5 \mathrm{~s}$. Then, ARMS-PCR amplification $\left(37^{\circ} \mathrm{C}\right.$ for $10 \mathrm{~min}, 95^{\circ} \mathrm{C}$ for 5 min, 40 cycles of $95{ }^{\circ} \mathrm{C}$ for $15 \mathrm{~s}$, and $60{ }^{\circ} \mathrm{C}$ for $35 \mathrm{~s}$ ) was performed using the 7500 system (Applied Biosystems; Thermo Fisher Scientific, Inc.). ROS1 fusions (fusion partners for ROS1: CD74, SLC34A2, SDC4, EZR, LRIG3, $T P M 3$, and GOPC) and EML4-ALK rearrangement were identified with commercial kits (Human ROS1 fusion Detection Kit, cat. No. YZYMT-022 and Human EML4-ALK fusion Detection Kit, cat. No. YZYMT-021, YZY Medical Co., Ltd., Wuhan, China).

\section{Statistical analysis}

Comparisons between two or more categorical variables were conducted using the Chi-square test and Fisher's exact test. Data were statistically performed on SPSS22.0 (Chicago, IL, USA). The results were considered statistically significant at $p<0.05$.

\section{Results}

\section{Clinicopathologic characteristics}

Among MPA cases, 36 patients fell into stage I, 11 into stage II, 6 into stage III, and 2 into stage IV. In LA, 39 (16 solid, 16 acinar, and 7 lepidic) fell into stage I, 12 (10 solid, 1 acinar, and 1 lepidic) into stage II, 8 (4 solid, 1 acinar, and 3 lepidic) into stage III, and 17 (13 solid and 4 lepidic) into stage IV. Seventy-two people had no smoking history, and fifty-nine were smokers, including former smokers and current smokers. The histological images of MPA and LA are presented in Fig. 1.

The MPA group consisted of $24(43.6 \%)$ women and $31(56.4 \%)$ men with an age at diagnosis ranging from
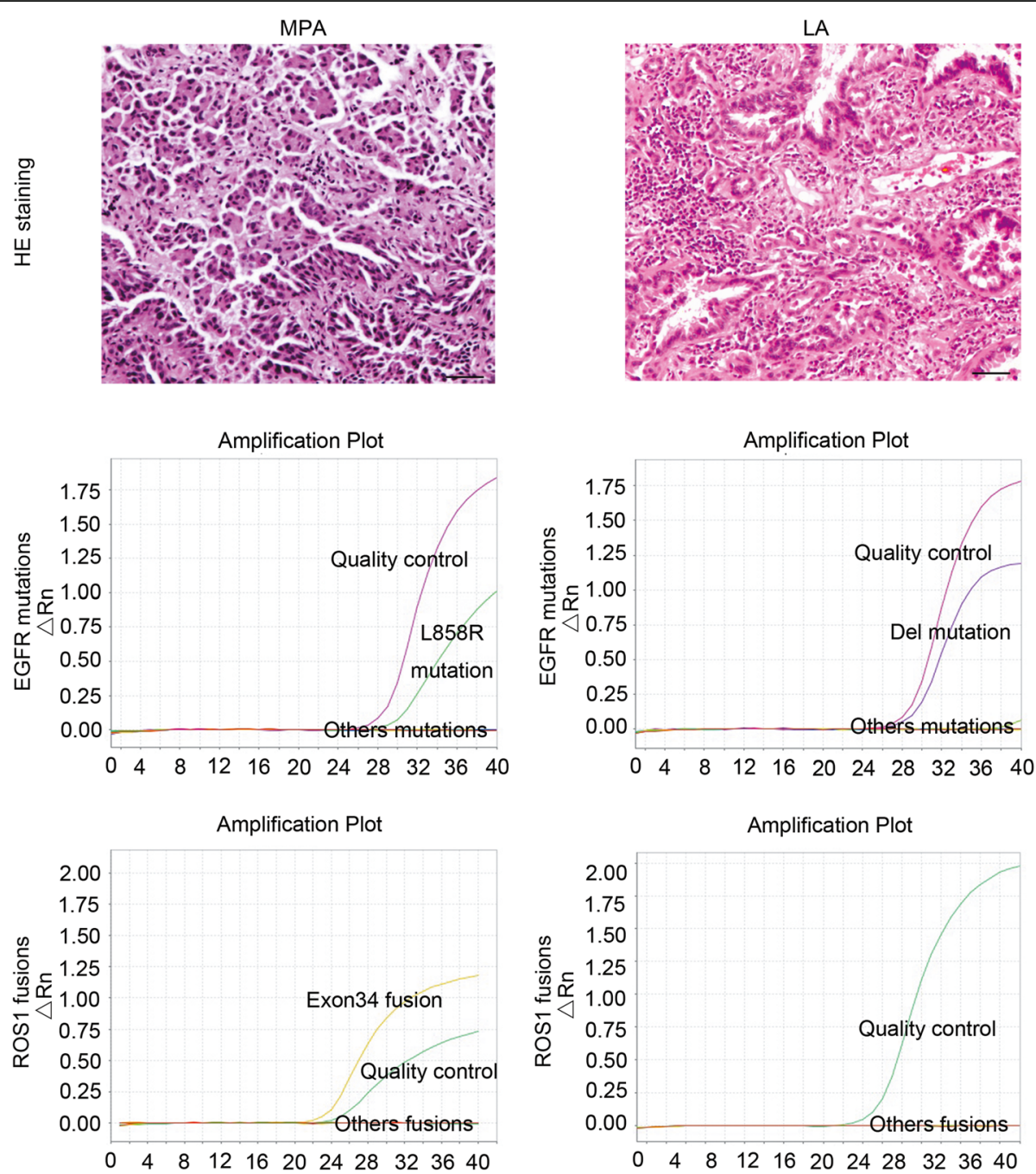

Fig. $1 \mathrm{Imm}$ unohistochemical staining and mutation analysis of MPA and LA patients. Three micrometers FFPE sections of MPA (patient 1) and LA (patient 16) were immunostained with hematoxylin and eosin ( $\times 100$ magnification). Scale bar $20 \mu \mathrm{m}$. Abbreviations: MPA, micropapillary lung adenocarcinoma; LA, lung adenocarcinoma without micropapillary component 
31 to 82 years (mean 62). In comparison, the LA group was composed of 38 (50.0\%) women and 38 men (50.0\%) with a mean age of 65 years (range, $46-81$ years). Compared to LA, MPA patients had a significantly younger age at diagnosis $(p=0.008)$, positive lymph node metastasis $(p=0.03)$, positive pleural invasion $(p=0.036)$, and earlier disease staging $(p=0.024)$ (Table 1$)$. However, the micropapillary pattern was not significantly associated with gender, smoking history, tumor size, and tumor differentiation (Table 1).

Table 1 Clinicopathologic and molecular characteristics of MPA and LA cases

\begin{tabular}{|c|c|c|c|c|}
\hline Variables & MPA $(\boldsymbol{n}=55)$ & $\mathrm{LA}(\boldsymbol{n}=76)$ & $x^{2}$ & $p$ \\
\hline Gender & & & 0.518 & 0.485 \\
\hline Female & $24(43.6 \%)$ & $38(50.0 \%)$ & & \\
\hline Male & $31(56.4 \%)$ & $38(50.0 \%)$ & & \\
\hline Age(years) & & & 7.452 & $0.008^{* *}$ \\
\hline$>65$ & $20(36.4 \%)$ & $46(60.5 \%)$ & & \\
\hline$\leq 65$ & $35(63.6 \%)$ & $30(39.5 \%)$ & & \\
\hline Smoking history & & & 0.191 & 0.723 \\
\hline Ever & $26(47.3 \%)$ & $33(43.4 \%)$ & & \\
\hline Never & $29(52.7 \%)$ & $43(56.6 \%)$ & & \\
\hline Tumor size (cm) & & & 0.058 & 0.851 \\
\hline$>3.0$ & 17(30.9\%) & $25(32.9 \%)$ & & \\
\hline$\leq 3.0$ & 38(69.1\%) & $51(67.1 \%)$ & & \\
\hline Lymphovascular invasion & & & 1.645 & 0.225 \\
\hline Present & $17(30.9 \%)$ & $16(21.1 \%)$ & & \\
\hline Absent & $38(69.1 \%)$ & $60(78.9 \%)$ & & \\
\hline Tumor differentiation & & & 0.179 & 0.835 \\
\hline Well/moderate & $43(78.2 \%)$ & $57(75.0 \%)$ & & \\
\hline Poor & $12(21.8 \%)$ & $19(25.0 \%)$ & & \\
\hline $\mathrm{N}$ status & & & 4.291 & $0.03^{*}$ \\
\hline NO & $31(56.4 \%)$ & $56(73.7 \%)$ & & \\
\hline N1/N2 & $24(43.6 \%)$ & $20(26.3 \%)$ & & \\
\hline Pleural invasion & & & 4.117 & $0.036^{*}$ \\
\hline Present & $15(27.3 \%)$ & $10(13.2 \%)$ & & \\
\hline Absent & $40(72.7 \%)$ & 66(86.8\%) & & \\
\hline Stage & & & 5.701 & $0.024^{*}$ \\
\hline |/II & 47(85.5\%) & $51(67.1 \%)$ & & \\
\hline III/IV & $8(14.5 \%)$ & 25(32.9\%) & & \\
\hline \multicolumn{5}{|l|}{ Mutation status } \\
\hline EGFR mutation & $42(76.4 \%)$ & $42(55.3 \%)$ & 6.175 & $0.016^{*}$ \\
\hline EML4-ALK fusion & $3(5.5 \%)$ & $1(1.3 \%)$ & 1.846 & 0.309 \\
\hline ROS1 fusion & $6(10.9 \%)$ & $1(1.3 \%)$ & 5.806 & $0.041^{*}$ \\
\hline
\end{tabular}

MPA micropapillary lung adenocarcinoma, $L A$ lung adenocarcinoma without micropapillary component

${ }^{*} p<0.05 ;{ }^{* *} p<0.01$ compared with LA

\section{Mutational status of classic oncogenes}

MPA and LA groups included 42 (76.4\%) and 42 (55.3\%) EGFR mutations, respectively. Interestingly, ROS1 rearrangements were highly enriched only in the MPA group $(6 / 55)$ but rarely in the LA group $(1 / 76)(p=0.041$, Table 1). Furthermore, we also discovered that different genetic driver alterations often co-existed in the MPA group, for instance, EGFR combined with ROS1 $(n=2)$ and EML4-ALK combined with ROS1 $(n=2)$, while only one LA case harbored EGFR combined with ROS1, suggesting that co-existent alterations of EGFR, ROS1, and $E M L 4-A L K$ were more frequent in MPA than in LA ( $p=$ 0.043 , Table 2). These results indicate the potential combined treatments of MPA with two different TKIs targeted to EGFR and ROS1.

To further explore the association between clinicopathologic characteristics and genetic driver alterations, we analyzed the general information and therapeutic outcomes in 5 lung adenocarcinoma patients with combined mutations. After surgical resection, all patients were treated with 3 months chemotherapy following with targeted therapy (TKIs). Follow-up data were accessible to all 5 patients after postoperative ranging from 0 to 12 months (median 10.8 months). All patients survived to the last day of follow-up. The results showed that four patients partially responded, and one patient suffered a recurrence according to RECIST 1.1 [29] (Table 3).

\section{Discussion and conclusions}

Accumulating evidence indicates that the co-existence of classic oncogenes, involving EGFR, ALK, ROS1, and $M E T$, was identified in lung adenocarcinoma patients, especially in younger and women patients without a smoking history. However, few studies have focused on the frequency of two-driver alterations of EGFR, ROS1,

Table 2 Coexistent genetic alterations including EGFR, ROS1, and EML4-ALK in MPA and LA cases

\begin{tabular}{llll}
\hline Variables & $\operatorname{MPA}(n=55)$ & $\mathrm{LA}(n=76)$ & $p$ \\
\hline Single alteration & & & $0.028^{*}$ \\
EGFR + & $40(72.7 \%)$ & $41(53.9 \%)$ & \\
ROS1 + & $2(3.6 \%)$ & 0 & \\
EML4-ALK+ & $1(1.8 \%)$ & $1(1.3 \%)$ & \\
Double alteration & & & $0.043^{*}$ \\
$\quad$ EGFR+; ROS1+ & $2(3.6 \%)$ & $1(1.3 \%)$ & \\
ROS1+; EML4-ALK+ & $2(3.6 \%)$ & 0 & $0.001^{* *}$ \\
No alteration & & & \\
$\quad$ EGFR-; ROS1-; EML4-ALK- & $8(14.5 \%)$ & $33(43.5 \%)$ & \\
\hline
\end{tabular}

MPA micropapillary lung adenocarcinoma, $L A$ lung adenocarcinoma without micropapillary component, EGFR+ EGFR mutation, EGFR- EGFR wild type, ROS1+ ROS1 fusion, ROS1- no ROS1 fusion, EML4-ALK+ EML4-ALK fusion, EML4ALK- no EML4-ALK fusion ${ }^{*} p<0.05 ;{ }^{* *} p<0.01$ compared with LA 
Table 3 General information and therapeutic outcomes on 5 patients with coexistent genetic alterations including EGFR, ROS1, and EML4-ALK in MPA and LA patients

\begin{tabular}{|c|c|c|c|c|c|}
\hline Patients & 1 & 2 & 3 & 4 & 5 \\
\hline Gender & Female & Male & Female & Male & Female \\
\hline Age (years) & 52 & 31 & 45 & 71 & 75 \\
\hline Smoking history & Never & Never & Never & Ever & Never \\
\hline $\begin{array}{l}\text { Lymphovascular } \\
\text { invasion }\end{array}$ & Absent & Present & Absent & Absent & Absent \\
\hline $\begin{array}{l}\text { Tumor } \\
\text { differentiation }\end{array}$ & Moderate & Moderate & Moderate & Moderate & Moderate \\
\hline Stage & T1bNOMO & T1CN1M0 & T1CNOMO & T1bNOMO & T1CNOMO \\
\hline Pathological type & MPA & MPA & MPA & MPA & LA \\
\hline Mutation status & ROS1+; EML4-ALK+ & ROS1+; EML4-ALK+ & EGFR L858R+; ROS1+ & EGFR L858R+; ROS1+ & EGFR 19-del+; ROS1+ \\
\hline $\begin{array}{l}\text { Therapeutic } \\
\text { intervention }\end{array}$ & $\begin{array}{l}\text { Surgery; } \\
\text { chemotherapy; } \\
\text { crizotinib }\end{array}$ & $\begin{array}{l}\text { Surgery; } \\
\text { chemotherapy; } \\
\text { crizotinib }\end{array}$ & $\begin{array}{l}\text { Surgery; chemotherapy; } \\
\text { EGFR inhibitors }\end{array}$ & $\begin{array}{l}\text { Surgery; chemotherapy; } \\
\text { EGFR inhibitors }\end{array}$ & $\begin{array}{l}\text { Surgery; chemotherapy; } \\
\text { EGFR inhibitors }\end{array}$ \\
\hline Outcomes & Partial response & Partial response & Partial response & Recurrence & Partial response \\
\hline
\end{tabular}

MPA micropapillary lung adenocarcinoma, LA lung adenocarcinoma without micropapillary component, EGFR+ EGFR mutation, ROS1+ ROS1 fusion, EML4-ALK+ EML4-ALK fusion

or EML4-ALK in MPA and LA. Therefore, we investigated the relationship between the most common oncogenic mutations and molecular pathological characteristics in Chinese lung adenocarcinoma patients.

Consistent with previous reports [30, 31], we here discovered that MPA has positive lymph node metastasis, positive pleural invasion, and earlier disease staging compared with LA (Table 1). Increasing studies have shown that a micropapillary component was associated with lymph node metastasis, pleural invasion, and an early recurrence in stage I patients, suggesting MPA had a poorer prognosis compared with those without micropapillary component or other histological subtypes [3239]. Our results further implied that the higher prevalence of lymph node metastasis and pleural invasion may be a valuable poor prognostic marker for MPA.

An investigation of 15 MPAs revealed that the mutational status of EGFR, KRAS, and BRAF harbored 73\% mutually exclusive mutations in the Western population [40]. A study involving 21 micropapillary predominant lung adenocarcinoma patients showed that oncogenic mutations in EGFR, HER2, and RET were apparently frequent in $95.2 \%$ Chinese people [22]. Here, our results manifested that the majority (47 out of $55,85.5 \%$ ) of MPA harbored the genetic driver alterations of EGFR (76.4\%), ROS1 (10.9\%), or EML4-ALK (5.5\%) from a Chinese cohort. Though previous cohort detected no ROS1 fusions [22], two another independent teams found ROS1 rearrangements in MPA [23, 24]. Therefore, there are no consistent conclusions about ROS1 rearrangements in MPA patients. Here, our cohort reported that $6 \mathrm{MPA}$ cases possessed ROS1 rearrangements. In the past, oncogenic mutations involving EGFR, KRAS, $A L K, R E T, R O S 1$, and MET were regarded as mutually independent events. However, two or more cancerassociated gene alterations were recently found in lung adenocarcinoma cases [41-44]. Our study indicated that $3.8 \%$ of lung adenocarcinoma cases harbored two-driver alterations of EGFR, ROS1, or EML4-ALK, including $7.3 \%$ of MPA cases and $1.3 \%$ of LA cases, and this result was in agreement with recent reports [41-45].

According to previous reports, patients with coalterations of EGFR, $A L K, R O S 1$, and other oncogenic drivers showed distinctive clinical responses to TKIs in lung adenocarcinoma [44, 46-48]. Yang et al. demonstrated that the median progression-free survival of gefitinib was 11.2 months in patients with concomitant EGFR and $A L K$ alteration [49]. Mao et al. indicated that the median progression-free survival of EGFR-TKIs and/ or $A L K / R O S 1$ inhibitor was 6.6 months in patients with concomitant EGFR and $A L K$ alteration [44]. However, $75 \%$ of patients with crizotinib treatment obtained disease control [44]. In the present study, all patients undertook the operation and chemotherapy initially and undertook subsequently targeted therapy. In addition, Watanabe et al. showed that the micropapillary component was associated with an early recurrence in stage I patients but not in advanced-stage patients, indicating MPA retained a high risk of early recurrence after 1-year surgery [39]. In the present study, among five patients with concomitant alterations of EGFR, ROS1, and $E M L 4-A L K$, four patients partially responded and one patient suffered a recurrence during 1 year follow-up. Our study provided evidence that lung adenocarcinoma patients with co-alterations of EGFR, ROS1, or EML4$A L K$ may benefit from TKIs treatment.

So far, there is little progress in digging the pathogenic mechanism of MPA or the treatment of this subtype by 
TKIs. Therefore, based on our findings, we will focus on elucidating the function of ROS1 rearrangement and EGFR mutations in MPA by establishing the cell and animal models both in vitro and in vivo in the future. In addition, we will verify the efficacy of one targeted TKI or combined TKIs for MPA and provide the potential treatment strategy.

In summary, we report for the first time the relationship between the most common oncogenic mutations and pathological characteristics in Chinese lung adenocarcinoma patients. We discover the higher incidence of ROS1 rearrangements and the coexistence of genetic alterations involving EGFR, ROS1, and EML4-ALK in MPA cases, indicating that targeting of ROS1 combined with $E G F R$ mutations may provide a novel therapeutic strategy for these patients. However, these results still should be supported by further studies with larger cases and in multi-centers.

\section{Abbreviations \\ MPA: Micropapillary lung adenocarcinoma; LA: Lung adenocarcinoma without micropapillary component; EGFR: Epidermal growth factor receptor; ROS1: ROS proto-oncogene 1 receptor tyrosine kinase; ALK: Anaplastic lymphoma kinase; EML4-ALK: Echinoderm microtubule-associated protein- Like 4-anaplastic lymphoma kinase; KRAS: Kirsten rat sarcoma viral oncogene; HER2: Erb-B2 receptor tyrosine kinase 2; RET: Rearranged during transfection; MET: Mesenchymal-epithelial transition; FFPE: Formalin-fixed paraffin- embedded; TKI: Tyrosine kinase inhibitor; TNM: Tumor node metastasis; IASL C: International Association for the Study of Lung Cancer; ATS: American Thoracic Society; ERS: European Respiratory Society; ARMS: Amplification refractory mutation system; PCR: Polymerase chain reaction; IHC: Immunohistochemistry; NGS: Next generation sequencing; FISH: Fluorescence in situ hybridization; RECIST 1.1: Response Evaluation Criteria in Solid Tumors version 1.1; ORR: Objective response rate; CR: Complete response; PR: Partial response; SD: Stable disease; PD: Progressive disease}

\section{Acknowledgements}

The authors would like to give our sincere thanks to professors Qilin Shi and Xiaolan Zhang (the First People's Hospital of Huzhou) for their help in analyzing the results of the HE staining.

\section{Authors' contributions}

XW designed and conceived this study. HX provided and evaluated the tumor tissues.

HMY performed the follow-up study. XLZ and YJ performed the experiments. XLZ and XW analyzed the data. All authors wrote and read the manuscript.

\section{Funding}

This work was funded by Zhejiang Province Science and Technology Department of Public Welfare Project (grant no. LGF18H160019, LGF20H160016), the Scientific Technology Projects of Health and Medicine of Zhejiang Province (grant no. WKJ-ZJ-1830, 2019KY207), and Huzhou Science and Technology Fund (grant no. 2017GY33).

\section{Availability of data and materials}

All data generated and analyzed during the present study are available from the corresponding author on reasonable request.

\section{Competing interest}

All authors declared no conflicts of interest with respect to the research, authorship, and/or publication of this article.

\section{Ethics approval and consent to participate}

This study was approved by the ethics committee of the First People's Hospital of Huzhou (grant no. 2015-012).

\section{Consent for publication}

The informed consent signature was provided by all patients.

\section{Author details}

${ }^{1}$ Central Laboratory, The First People's Hospital of Huzhou, No. 158 Guangchang Back Road, Huzhou, 313000 Zhejiang, People's Republic of China. ${ }^{2}$ Department of Cardiothoracic Surgery, The First People's Hospital of Huzhou, Huzhou 313000, People's Republic of China. ${ }^{3}$ Department of Pathology, The First People's Hospital of Huzhou, Huzhou 313000, People's Republic of China.

Received: 17 February 2020 Accepted: 3 July 2020

Published online: 16 July 2020

\section{References}

1. Didkowska J, Wojciechowska U, Manczuk M, et al. Lung cancer epidemiology: contemporary and future challenges worldwide. Ann Transl Med. 2016;4(8):150-61.

2. Travis WD, Brambilla E, Nicholson AG, et al. The 2015 World Health Organization classification of lung tumors: impact of genetic, clinical and radiologic advances since the 2004 classification. J Thorac Oncol. 2015;10(9): $1243-60$

3. Travis WD, Brambilla E, Noguchi M, et al. International Association for the Study of Lung Cancer/American Thoracic Society/European Respiratory Society international multidisciplinary classification of lung adenocarcinoma. J Thorac Oncol. 2011:6(2):244-85.

4. Marx A, Chan JK, Coindre JM, et al. The 2015 World Health Organization classification of tumors of the thymus: continuity and changes. J Thorac Oncol. 2015;10(10):1383-95.

5. Zhang T, Wang J, Su Y, et al. Is MPP a good prognostic factor in stage III lung adenocarcinoma with EGFR exon 19 mutation? Oncotarget. 2017;8(25): 40594-605

6. Satoh Y, Hoshi R, Horai T, et al. Association of cytologic micropapillary clusters in cytology samples with lymphatic spread in clinical stage I lung adenocarcinomas. Lung Cancer. 2009;64(3):277-81.

7. Gao S, Stein S, Petre EN, et al. Micropapillary and/or solid histologic subtype based on pre-treatment biopsy predicts local recurrence after thermal ablation of lung adenocarcinoma. Cardiovasc Intervent Radiol. 2018;41(2): 253-9.

8. Wang S, Li J. Second-generation EGFR and ErbB tyrosine kinase inhibitors as first-line treatments for non-small cell lung cancer. Onco Targets Ther. 2019: 12(15):6535-48.

9. Bi R, Bai $Q$, Zhu X, et al. ALK rearrangement: a high-frequency alteration in ovarian metastasis from lung adenocarcinoma. Diagn Pathol. 2019;14(1):96-105.

10. Morris TA, Khoo C, Solomon BJ. Targeting ROS1 rearrangements in nonsmall cell lung cancer: crizotinib and newer generation tyrosine kinase inhibitors. Drugs. 2019;79(12):1277-86.

11. Dogan $S$, Shen R, Ang DC, et al. Molecular epidemiology of EGFR and KRAS mutations in 3,026 lung adenocarcinomas: higher susceptibility of women to smoking-related KRAS-mutant cancers. Clin Cancer Res. 2012;18(22):6169-77.

12. Sun $Y$, Ren $Y$, Fang $Z$, et al. Lung adenocarcinoma from east Asian neversmokers is a disease largely defined by targetable oncogenic mutant kinases. J Clin Oncol. 2010;28(30):4616-20.

13. Wu JY, Yu CJ, Chang YC, et al. Effectiveness of tyrosine kinase inhibitors on "uncommon" epidermal growth factor receptor mutations of unknown clinical significance in non-small cell lung cancer. Clin Cancer Res. 2011;17(11):3812-21.

14. Wu YL, Lee JS, Thongprasert S, et al. Intercalated combination of chemotherapy and erlotinib for patients with advanced stage non-small-cell lung cancer (FASTACT-2): a randomised, double-blind trial. Lancet Oncol. 2013;14(8):777-86

15. Soda M, Choi YL, Enomoto M, et al. Identification of the transforming EML4ALK fusion gene in non-small-cell lung cancer. Nature. 2007;448(7153):561-6.

16. Rikova K, Guo A, Zeng Q, et al. Global survey of phosphotyrosine signaling identifies oncogenic kinases in lung cancer. Cell. 2007;131(6):1190-203.

17. Garg A, Batra U, Choudhary P, et al. Clinical predictors of response to EGFRtyrosine kinase inhibitors in EGFR-mutated non-small cell lung cancer: a real-world multicentric cohort analysis from India. Curr Probl Cancer. 2020; 44(3):100570-80.

18. De Giglio A, Lamberti G, Facchinetti F, et al. Treatment patterns and clinical outcomes among patients with ROS1-rearranged non-small-cell lung cancer progressing on crizotinib. Clin Lung Cancer. 2020;51525-7304(20):30087-5. 
19. Zhang $Y$, Zeng $L$, Zhou $C$, et al. Detection of nonreciprocal/reciprocal ALK translocation as poor predictive marker in patients with first-line crizotinibtreated ALK-rearranged NSCLC. J Thorac Oncol. 2020;15(6):1027-36.

20. Shackelford RE, Ansari JM, Wei EX, et al. Anaplastic lymphoma kinase rearrangements in non-small-cell lung cancer: novel applications in diagnostics and treatment. Pharmacogenomics. 2017;18(12):1179-92.

21. Teixido C, Karachaliou N, Peg V, et al. Concordance of IHC, FISH and RT-PCR for EML4-ALK rearrangements. Transl Lung Cancer Res. 2014;3(2):70-4

22. Zhang $Y$, Wang $R$, Cai $D$, et al. A comprehensive investigation of molecula features and prognosis of lung adenocarcinoma with micropapillary component. J Thorac Oncol. 2014;9(12):1772-8.

23. Blaukovitsch $M$, Hofer J, Hutarew $G$, et al. ROS1 mutation and treatment with crizotinib in a 30-year old Caucasian woman with stage IV non-small cell lung cancer/adenocarcinoma and complete remission. Thorac Cancer. 2014:5(5):455-9.

24. Jin Y, Sun PL, Park SY, et al. Frequent aerogenous spread with decreased Ecadherin expression of ROS1-rearranged lung cancer predicts poor diseasefree survival. Lung Cancer. 2015;89(3):343-9.

25. Barlesi F, Mazieres J, Merlio JP, et al. Routine molecular profiling of patients with advanced non-small-cell lung cancer: results of a 1-year nationwide programme of the French cooperative thoracic intergroup (IFCT). Lancet. 2016;387(10026):1415-26.

26. Ju L, Han M, Zhao C, et al. EGFR, KRAS and ROS1 variants coexist in a lung adenocarcinoma patient. Lung Cancer. 2016;95(5):94-7.

27. Zhu YC, Xu CW, Ye XQ, et al. Lung cancer with concurrent EGFR mutation and ROS1 rearrangement: a case report and review of the literature. Onco Targets Ther. 2016;9(15):4301-5.

28. Wang C, Yang J, Lu M. Micropapillary predominant lung adenocarcinoma in stage IA benefits from adjuvant chemotherapy. Ann Surg Oncol. 2020;27(6): 2051-60.

29. Eisenhauer EA, Therasse P, Bogaerts J, et al. New response evaluation criteria in solid tumours: revised RECIST guideline (version 1.1). Eur J Cancer. 2009; 45(2):228-47.

30. Dai C, Xie H, Kadeer X, et al. Relationship of lymph node micrometastasis and micropapillary component and their joint influence on prognosis of patients with stage I lung adenocarcinoma. Am J Surg Pathol. 2017:41(9):1212-20.

31. Pyo JS, Kim JH. Clinicopathological significance of micropapillary pattern in lung adenocarcinoma. Pathol Oncol Res. 2018;24(3):547-55.

32. Yoshizawa A, Motoi N, Riely GJ, et al. Impact of proposed IASLC/ATS/ERS classification of lung adenocarcinoma: prognostic subgroups and implications for further revision of staging based on analysis of 514 stage I cases. Mod Pathol. 2011;24(5):653-64.

33. Warth A, Muley T, Meister M, et al. The novel histologic International Association for the Study of Lung Cancer/American Thoracic Society/European Respiratory Society classification system of lung adenocarcinoma is a stageindependent predictor of survival. J Clin Oncol. 2012;30(13):1438-46.

34. Hung JJ, Jeng WJ, Chou TY, et al. Prognostic value of the new International Association for the Study of Lung Cancer/American Thoracic Society/ European Respiratory Society lung adenocarcinoma classification on death and recurrence in completely resected stage I lung adenocarcinoma. Ann Surg. 2013;258(6):1079-86

35. Nitadori J, Bograd AJ, Kadota K, et al. Impact of micropapillary histologic subtype in selecting limited resection vs lobectomy for lung adenocarcinoma of $2 \mathrm{~cm}$ or smaller. J Natl Cancer Inst. 2013;105(16):1212-20.

36. Campos-Parra AD, Aviles A, Contreras-Reyes $\mathrm{S}$, et al. Relevance of the novel IASLC/ATS/ERS classification of lung adenocarcinoma in advanced disease. Eur Respir J. 2014;43(5):1439-47.

37. Russell PA, Barnett SA, Walkiewicz M, et al. Correlation of mutation status and survival with predominant histologic subtype according to the new IASLC/ATS/ERS lung adenocarcinoma classification in stage III (N2) patients. J Thorac Oncol. 2013;8(4):461-8.

38. Cha MJ, Lee HY, Lee KS, et al. Micropapillary and solid subtypes of invasive lung adenocarcinoma: clinical predictors of histopathology and outcome. J Thorac Cardiovasc Surg. 2014;147(3):921-8 e922.

39. Watanabe K, Sakamaki K, Ito H, et al. Impact of the micropapillary component on the timing of recurrence in patients with resected lung adenocarcinoma. Eur J Cardiothorac Surg. 2020:ezaa138. https://doi.org/10. 1093/ejcts/ezaa138.

40. De Oliveira Duarte Achcar R, Nikiforova MN, Yousem SA. Micropapillary lung adenocarcinoma: EGFR, K-ras, and BRAF mutational profile. Am J Clin Pathol. 2009;131(5):694-700
41. Song Z, Yu X, Zhang Y. Clinicopathological characteristics and survival of ALK, ROS1 and RET rearrangements in non-adenocarcinoma non-small cell lung cancer patients. Cancer Biol Ther. 2017;18(11):883-7.

42. Won JK, Keam B, Koh J, et al. Concomitant ALK translocation and EGFR mutation in lung cancer: a comparison of direct sequencing and sensitive assays and the impact on responsiveness to tyrosine kinase inhibitor. Ann Oncol. 2015;26(2):348-54

43. Zhang $X$, Zhang S, Yang $X$, et al. Fusion of EML4 and ALK is associated with development of lung adenocarcinomas lacking EGFR and KRAS mutations and is correlated with ALK expression. Mol Cancer. 2010;9:188-99.

44. Mao Y, WU S. ALK and ROS1 concurrent with EGFR mutation in patients with lung adenocarcinoma. Onco Targets Ther. 2017;10:3399-404

45. Cancer Genome Atlas Research N. Comprehensive molecular profiling of lung adenocarcinoma. Nature. 2014;511(7511):543-50.

46. Van Der Steen N, Mentens Y, Ramael M, et al. Double trouble: a case series on concomitant genetic aberrations in NSCLC. Clin Lung Cancer. 2018;19(1): $35-41$.

47. Lin JJ, Ritterhouse LL, Ali SM, et al. ROS1 fusions rarely overlap with other oncogenic drivers in non-small cell lung cancer. J Thorac Oncol. 2017;12(5): $872-7$.

48. Wiesweg M, Eberhardt WE, Reis $\mathrm{H}$, et al. High prevalence of concomitant oncogene mutations in prospectively identified patients with ROS1-positive metastatic lung cancer. J Thorac Oncol. 2017;12(5):54-64

49. Yang JJ, Zhang XC, Su J, et al. Lung cancers with concomitant EGFR mutations and ALK rearrangements: diverse responses to EGFR-TKI and crizotinib in relation to diverse receptors phosphorylation. Clin Cancer Res. 2014;20(5):1383-92.

\section{Publisher's Note}

Springer Nature remains neutral with regard to jurisdictional claims in published maps and institutional affiliations.
Ready to submit your research? Choose BMC and benefit from:

- fast, convenient online submission

- thorough peer review by experienced researchers in your field

- rapid publication on acceptance

- support for research data, including large and complex data types

- gold Open Access which fosters wider collaboration and increased citations

- maximum visibility for your research: over $100 \mathrm{M}$ website views per year

At BMC, research is always in progress.

Learn more biomedcentral.com/submissions 